\title{
Prevalence of Child and Adult Sexual Abuse and Risk Taking Practices Among HIV Serodiscordant African-American Couples
}

\author{
The NIMH Multisite HIV/STD Prevention Trial for African American Couples Group
}

Published online: 25 May 2010

(C) The Author(s) 2010. This article is published with open access at Springerlink.com

\begin{abstract}
This study reports the prevalence of child (CSA) and adult (ASA) sexual abuse among 535 African American HIV serodiscordant couples from four major United State cities, and its relationship to personal and couple related vulnerabilities and HIV risk factors. As part of a randomized, clinical trial, CSA and ASA histories were obtained through face-to-face interviews. Results indicate that HIV positive women were significantly more likely to report one kind of abuse (32.32\%), either before or
\end{abstract}

The NIMH Multisite HIV/STD Prevention Trial for African American Couples Study Group

Steering Committee Nabila El-Bassel, DSW (PI) - Columbia

Gina Wingood, ScD, MPH (PI) - Emory

Gail E. Wyatt, PhD (PI) - UCLA

John B. Jemmott, III, PhD (PI) - Penn

Willo Pequegnat, $\mathrm{PhD}$ - NIMH

J. Richard Landis, PhD (PI) - DCC

Co-Investigators Scarlett Bellamy, ScD - DCC

Louisa Gilbert, PhD Candidate - Columbia

Robert H. Remien, PhD - Columbia

Susan Witte, $\mathrm{PhD}$ - Columbia

Elwin $\mathrm{Wu}, \mathrm{PhD}$ - Columbia

Ralph DiClemente, PhD - Emory

Hector Myers, PhD - UCLA

Loretta Sweet Jemmott, PhD, RN, FAAN - Penn

David Metzger, PhD - Penn

Data Coordinating Center (DCC - Penn) Shawn Ballard, MS

Trina Brown

Quincy Greene

Christopher Helker, RN, MSPH

Nancy Robinson, $\mathrm{PhD}$

Lynne Allen-Taylor, $\mathrm{PhD}$

Dina Appleby, MS

Evelyn Crowley, $\mathrm{PhD}$

Project Directors Angela Ankoma MSSW, MPH - Columbia

Deidre Ashton, MSSW - Columbia

Dawn A. Goddard, MSS - Columbia

Tamu Daniel, MPH - Emory

Tina Henderson, PhD - UCLA

Inna Rivkin, PhD - UCLA

Cynthia M. Green, MA - Penn since age 18 or both (32.6\%). HIV-positive men $(34.9 \%)$ were significantly more likely to report CSA than HIVnegative men $(22.0 \%)$. Overall, $72 \%$ of couples reported that one or both had CSA histories. These findings underscore the heightened emotional vulnerability, and STI and HIV transmission risk taking practices, associated with sexual abuse. Sexual abuse histories among couples should be assessed to better understand how these histories may contribute to couples dynamics and risk-taking practices.

Facilitators Jeffery Brently, MSW - Columbia

Rebecca D. Cheraquit, MSSW - Columbia

Deborah Gray - Columbia

Linda Hakim - Columbia

Bright Sarfo - Columbia

Kijana Saunders - Columbia

Dawn Simmons, MSW - Columbia

Keisha Wilson, MSW - Columbia

Nikia D. Braxton, MPH - Emory

Christina Camp, PhD - Emory

Anita Conner, MPH - Emory

Jevon Gibson - Emory

Alvin Harmon, PhD - Emory

Teaniese Latham, MPH - Emory

Tiffany Pennick-Walters, MPH - Emory

Kenneth Rucker - Emory

Shammara Steinback, MPH - Emory

Phillip Williams - Emory

Richard Williams, PhD - Emory

Shauni Williams - Emory

Kevin Chancy, PsyD - UCLA

Frank Levels - UCLA

Nathaniel Thomas, PhD - UCLA

Reginald Bennett, MS - Penn

Shirley Bryson, MSW - Penn

Salema Curtis, MPH - Penn

Michelle Jones, MS - Penn

Phyllis Jones, MSW - Penn

Malachi Moore, MS - Penn

Charles Patterson, MA - Penn

Marcia Penn, MS - Penn

Alicia Samuel, M.Ed. - Penn 
Keywords HIV . Child sexual abuse .

Adult sexual abuse - Serodiscordant .

Sexual re-victimization $\cdot$ African-American couples

\section{Introduction}

In the United States, African American women and men continue to be significantly impacted by HIV/AIDS [1]. The rate of AIDS among African American women is nearly 23 times that of white women, while the rate among African American men is eight times the rate for white men [2]. Although African Americans only account for $12.4 \%$ of the U.S. population [3], they constitute almost half of all new HIV infections [2].

Heterosexual contact is the primary mode of HIV infection for African American women and the third most common mode of transmission for African-American men [2]. Attention is being directed to heterosexual AfricanAmerican couples who are serodiscordant, where one member of the couple is HIV-positive and the other is HIVnegative. Although HIV-related behaviors are often better understood within the context of sexual partnerships [4], little is known about factors affecting the sexual histories of couples. One partner's personal history or contribution to interpersonal dynamics may impact the overall risk and health of the couple [5-8]. Most HIV couples studies focus on marital or sexual satisfaction, the impact of extra-

Randy Shine, MPH - Penn

Ralph Stevenson, MA - Penn

Robert Tate, M.Ed. - Penn

Michael Taylor, MSW - Penn

Charlotte Wroton, MS - Penn

Recruiters Derryck Griffith - Columbia

Pearl Johnson - Columbia

Lisa Matthews - MPH, EdD Candidate - Columbia

Rhonda Mendoza - Columbia

Allan Winkle - Columbia

Jill Daugherty, MPH - Emory

Deja Er, MPH - Emory

Linda Felix, MAT - Emory

Meklit Hailemeskal, MPH - Emory

Toya Howard - Emory

Tamika Hoyte, MPH - Emory

Jamie Smith, MPH - Emory

Lisa Smith, MPH - Emory

Les DeMorst - UCLA

Rotrease Regan, RN, MPH - UCLA

Elsa Rogers - UCLA

Karen Carter - Penn

Calvin Collier, BS - Penn

Mikia Croom, BS - Penn

Dionna Samuel, MS - Penn

Joseph Sosa, BS - Penn

Brian Taylor, BS - Penn

Supervisors Tamara S. Bryan, $\mathrm{PhD}$ - Columbia

LaShun Robinson-Simpson, PhD - Emory

Christina Camp, PhD - Emory

Tamra Loeb, PhD - UCLA marital problems on relationships $[9,10]$, or the traumatic effects of marital disruption [11]. Identifying additional factors that may also heighten the risks that couples encounter in HIV serodiscordant relationships have yet to be adequately studied [5].

Sexual abuse across the life course is a factor that can affect HIV-related risks for couples. Child sexual abuse (CSA), defined as unwanted or coerced sexual contact before age 18 , is a common experience among women of all ethnicities [12]. The prevalence of child sexual abuse for HIV-negative women is approximately one in three, but for HIV-positive women it is one in two in the United States [13-16]. However, these findings were reported for women who were not necessarily in relationships. There are few studies describing the prevalence of sexual abuse among self-identified heterosexual men. Estimates of sexual abuse among mostly men who have sex with men vary widely, from 4 to $76 \%$ [13]. Discrepancies in these rates may be due to differences in what constitutes abuse, how questions were asked, the samples studied [17, 18], and more importantly, to the reluctance of males to disclose these incidents [19]. Boys at highest risk tend to be younger than 13, non-white and poor [20]. Problems with prevalence rates notwithstanding, incidents of child sexual abuse before age 18 tend to form the template for long-term effects that extend beyond the personal difficulties of the survivor and influence future relationship dynamics [21]. As child sexual abuse is a form of interpersonal violence,

John Williams MD - UCLA

Lynette Gueits, MPH - Penn

Laboratory Cynthia Bayer, MS, CRNP - Penn

Angela Caliendo, MD, PhD - Emory

Shalonda Freeman, PhD - Emory

Jessica Ingersoll - Emory

Lisa Maslankowski, MD - Penn

Debra McGee-Smith, NP - UCLA

Patrice Moorer, MS - Emory

Michelle Mott, MSN, FNP-C - Emory

Bennie Woodard, MPH - Emory

Data Collectors Claudette Bannerman - Columbia

Warren Blake - Columbia

Tiffany Bratts MPH - Columbia

Olivia Copeland, Ed.D - Columbia

Daisy De Jesus-Sosa - UCLA

Adefunke Faly, MPH - Emory

Meklit Hailemeskal, MPH - Emory

Tamika Hoyte, MPH - Emory

Janet Hsu, BS - Penn

Heather Irobunda - Columbia

Shakaria Johnson, MPH - Emory

Frandy Napoleon - Columbia

Karen Williams - UCLA

Sonya Combs, MS - Penn

Mathew MacDonald, BS - Penn

Lolita Roy MSSW - Columbia

Dalena White, MBA - Penn

Pandora Woods, BS - Penn

Crystal Wyatt - Penn 
often by someone with whom the child has a close relationship, survivors are likely to experience intimate relationship problems as adults [22]. In fact, women with CSA histories report less intimate relationship satisfaction, less trust of their partners, and poorer communication than women without CSA histories [23].

Child sexual abuse survivors are also more likely to report being victims of adult sexual abuse (ASA) or rape [4, 17, 24-26]. African American women with CSA are more likely to be raped as adults compared to women of other ethnic backgrounds, due primarily to the effects of poverty and living in highly dense, urban areas [27]. One study showed African American and Latino men at risk for HIV with CSA histories were 6.8 times more likely to report unwanted sexual activity after age 13 than those without CSA histories [28].

Although past studies have incorporated couples into their designs, most studies treat each person's data independently and focus on reducing individual risk taking practices [29]. The present study focused on couples, so that one person would not have to explain the need to change behaviors that two individuals may engage in. Addressing individuals in a couple requires that both persons assume responsibility for themselves and for each other. Given that gender and culture bound traditions endorse women's compliance with their partner's sexual advances [30-32], women with histories of early sexual abuse may have difficulties in self advocacy, and may not communicate concerns about condom use or sexual behaviors that may increase risks for HIV/STD transmission to the uninfected partner [21, 33], However, since we do not have adequate information on couples [34], the present study attempts to address this limitation.

While the relationship between early abusive sexual experiences and HIV-related sexual practices has been included in HIV prevention interventions [32, 35, 36], most of this research focuses on individuals and primarily women [11, 37]. Other studies that report histories of child or adult sexual abuse with couples have included ethnic groups other than African Americans [38, 39] or report findings from large international research with results that are difficult to generalize to U.S. populations [40-45].

Individuals with CSA histories may also be more likely to use maladaptive coping strategies (e.g., substance use) [46, 47], and report an inability to protect themselves from future abuse within their relationships [48]. Women with early and chronic sexual abuse have a seven-fold increase in HIV risk behavior, including intravenous drug use, sexually transmitted infections (STI's) [14, 49], and anal

The NIMH Multisite HIV/STD Prevention Trial for African American Couples Group

Bethesda, MD, USA

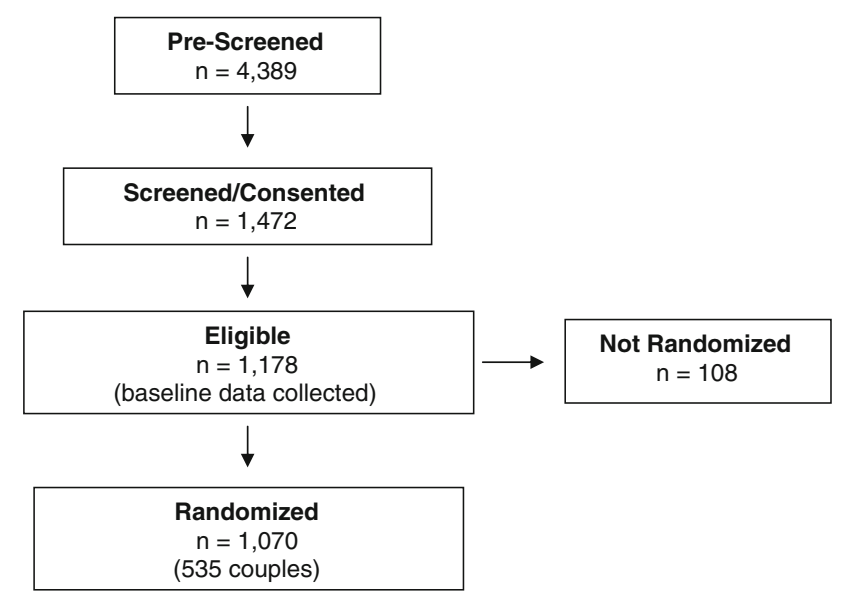

Fig. 1 AAC participant flow; pre-screening to randomization, Note: there were no observed statistical differences between participants who were eligible and not randomized compared to those who were eligible and randomized for a number of key demographic characteristics, including age, education, employment status, income and insurance status. Randomized participants were, however, more likely to be married compared to those eligible couples who were not randomized (340 (32.35\%) versus $(19.80 \%) ; P<0.01)$

sex without condoms [24]. Lower condom self-efficacy has also been reported [50]. Women with histories of CSA may also be likely to have more sexual partners $[49,51,52]$ and report higher rates of sexual revictimization $[27,32,53]$. Conversely, once women with CSA histories become infected with HIV, they may be less likely to engage in regular sexual activity with partners [36].

Young male CSA survivors report engaging in a range of self-destructive behaviors including unprotected anal intercourse while intoxicated, hypersexual behavior, and unprotected sex with multiple partners [54]. These behaviors are associated with significant distress from past abuse, possibly contributing to sexual identity confusion and sexually-related problems $[13,55-58]$. It may be useful to consider the gender of the HIV-infected partner as a predictor of the pattern of HIV-related risk-taking behaviors, to better understand what couples may need to address in clinical treatment and interventions.

The purpose of this study was to report the prevalence of child and adult sexual abuse histories among HIV-serodiscordant African-American couples in four U.S. cities by the gender of the infected partner. Second, we examined the relationship between histories of sexual abuse in childhood, adulthood, or both, in individual- and couplerelated outcomes that increase HIV and STI transmission risks. We expect higher sexual abuse and sexual re-victimization rates among HIV-positive African American women compared to their HIV-negative counterparts and increased risk taking practices among HIV positive women whose partners are HIV negative. 


\section{Methods}

\section{Study Design}

This paper used baseline data from the Eban study, a twoarm, couples-based randomized controlled intervention trial of HIV serodiscordant African-American couples from four U.S. cities (Atlanta, GA, Los Angeles, CA, New York, NY, and Philadelphia, PA). The study tested the efficacy of a couple-focused HIV/STD risk reduction intervention vs. an individual-focused health promotion intervention in reducing sexual risk behaviors and STD incidence (For more details on the study design see Bellamy [59], NIMH Multisite HIV/STD Prevention Trial for African-American Couples Group [60-62], and "Risky Sexual Behavior and Correlates of STD Prevalence..." (in this paper) [63]).

\section{The Study Sample and Recruitment of the Couples}

The study includes 535 couples (1070 individuals) recruited from HIV care clinics, HIV testing and counseling sites, primary care clinics, substance abuse treatment programs, churches and HIV/AIDS ministries, HIV/AIDS services providers and community-based coalitions of advocacy organizations. Participants met specific study criteria (see NIMH Multisite HIV/STD Prevention Trial for African-American Couples Group [64] for greater detail on study recruitment and criteria). Study recruitment procedures and eligibility criteria are described in "Risky Sexual Behavior and Correlates of STD Prevalence among African American HIV Serodiscordant Couples" in this issue [63].

\section{Staff Training}

There were 15 interviewers trained to administer the ACASI and the face-to-face version of the modified Wyatt Sex History Questionnaire [12] that was used to assess child and adult sexual abuse. While research indicates that social desirability of responses may be facilitated by the ACASI, there is significant variance in an individual's perception of sexual experiences that meet criteria as sexual abuse [65]. Face-to-face administration of the sexual abuse questions allowed for the participants to clarify and discuss: (1) incidents that may or may not meet criteria (such as before or since age 18); (2) the meaning of terms like 'anal sex (for women) is where the perpetrator puts his penis in your bottom or behind' that may be unclear or confusing; and (3) incidents that may not have been reported or disclosed prior to the interview. The training protocol included a discussion of skills needed for face-toface interviews and the importance of interviewers avoiding body language or posturing that might influence participant responses; how to avoid 'burn out' which may lead to the inability to separate the interviewer's personal history from the participant's experiences; how to report incidents of sexual and physical abuse, if needed; and how to handle emotional responses to questions about trauma. The training also included the importance of supervisors discussing all aspects of data collection with interviewers to ensure their consistency throughout the study. Mock interviews of sexual abuse were demonstrated and scored by interviewers with high inter-rater reliability $(\alpha=0.95)$. A clinical psychologist with expertise in coding sexual abuse reviewed and corrected any coding errors of each incident across four sites prior to analyses of these data (Fig. 1).

\section{Measures}

At baseline, data were obtained from three sources. First, participants completed a 90-minute Audio ComputerAssisted Survey Interview (ACASI), which assessed sociodemographic and relationship characteristics, sexual behaviors and condom use, and psychosocial mediators that had sound psychometric properties and had previously been implemented with adult African-American populations. Although both participating male and female partners completed the same ACASI assessments, the sexual behavior items were written to be appropriate for each specific gender. Subsequently, a trained African-American interviewer administered validated and reliable assessments on sexual and physical abuse and a brief index assessing study participants' commitment to the AfricanAmerican community. Finally, males provided a urine specimen and women provided two vaginal swab specimens that were assayed for three STDs and HIV testing. For more detail see NIMH Multisite HIV/STD Prevention Trial for African-American Couples Group [64].

\section{Sociodemographic Characteristics}

Characteristics of the sample were reported and included items such as participant's age, education, employment status, income, living arrangement, marital status, and length of their relationship. Participants who responded "excellent" or "very good" to the following question were considered to have excellent or very good general health: "In general, how would you rate your overall quality of life?" Hepatitis C status was determined by summarizing participant responses to the following item: "Has your doctor or nurse ever told you that you have Hepatitis C?" Participants who responded "yes" to this item were denoted as Hepatitis C positive. Insurance status was determined by responses to the following item: "Do you currently have health care insurance, including government-sponsored insurance such as Medicaid or Medical?" 
To assess quality of life, two responses were summed related to feelings about life now and life one year from now; scores ranged from 2 (worst possible life now and 1 year from now) to 20 (best possible life now and 1 year from now). Participants were asked to recall the number of children that depend on them for the majority of their food and shelter.

\section{Definitions of Child and Adult Sexual Abuse}

Child sexual abuse (CSA) is a multidimensional construct that is defined as sexual incidents before age 18 (the age of legal consent) [66], which involved: (1) involuntary or coerced sexual experiences of a male or female (regardless of the age of the perpetrator), (2) a male or female of the same age that were against their will, (3) a male or female with a perpetrator who was 5 years or older, or (4) a male or female with a perpetrator who was older than 18 years. Components of this definition also highlight the power imbalance and cognitive inability of survivors younger than 18 years to understand the behavior or consequences of the sexual context (statutory rape) [67,68], and often involves multiple incidents over time [69, 70]. Adult sexual abuse (ASA) is defined as attempted or completed sexual acts of rape since age 18. Research has shown that there is a link between child sexual abuse and adult re-victimization, with ASA being almost five times more likely among those with histories of CSA [51].

\section{Assessment of CSA and ASA}

Men and women were asked about their child and adult sexual experiences using a modified version of the Wyatt Sex History Questionnaire [12]. This instrument had a combination of forced-choice and open-ended response options which allowed participants to clarify what incidents met the definition of abuse and facilitated memory recall by using calendars, as well as bounding and framing techniques to describe important events [12]. To assess CSA, participants were asked seven questions (yes/no items), regarding attempted or completed vaginal or anal intercourse, oral copulation to either victim or perpetrator, and digital penetration of victim or perpetrator. If participants responded "yes" to any of the questions, they were classified as having experienced CSA. To assess severity, they were asked questions about their age at the time of the incident, the age of the perpetrator, the relationship of the perpetrator to the victim (e.g., parent, relative, stranger, etc.), if the incident was consensual, and whether it had occurred with someone else before the age of 18 .

To assess ASA, men and women were asked whether or not someone forced their penis or an object in their bottom (or vagina for women) since age 18. If participants answered "yes" they were classified as having experienced ASA.

\section{Couple-Level Abuse Measure}

Couple-level abuse scores (e.g., whether neither, one, or both partners reported abuse histories) included the total number of abuse experiences of both male and female partners.

\section{Relationship Characteristics}

Study participants were asked questions that addressed relationship characteristics including length of relationship, whether or not participants were married to or separated from their study partner, and quality of relationship. A general scale developed by Hendrick [71] to measure the quality of satisfaction in intimate relationships was used to assess the quality of the relationship. The scale consists of seven items and summary scores range from 7 (low satisfaction) to 35 (high satisfaction). Questions on this scale include: (1) "How well does your study partner meet your needs?" and (2) "In general, how satisfied are you with your relationship?" This measure has been used by a range of populations including urban African-American and Latino women [72].

\section{Past Experiences that Increase Vulnerability and Drug Related, Housing, and Psychological Problems}

Prior incarceration, drug treatment program and residential treatment program histories were determined by the following three items: "Have you ever spent time in jail or prison?", "Have you ever spent time in an impatient drug treatment program?" and "Have you ever spent time in other residential programs?", respectively. The Cutting down, Annoyance by criticism, Guilty feeling and Eyeopeners (CAGE) brief screener was used to measure lifetime alcohol dependence [73] and history of heavy drug use and dependence was measured using the Texas Christian Drug Screen II (TCUDS) [74]. Alcohol and drug problems were characterized by CAGE scores greater than or equal to two and by TCUDS scores greater than or equal to three, respectively.

\section{Relationship-Based Risks}

Participants provided data on the use of male and female condoms during sex and different types of sexual behaviors they had engaged in with study partners (vaginal, anal and oral intercourse) over the past 90 days. We selected the 90 day time period in order to allow sufficient time for 
Table 1 Demographics of participants meeting eligibility requirements, $\mathrm{N}=535$ couples

\begin{tabular}{|c|c|c|c|c|}
\hline & All Participants $(N=1070)$ & Males $(N=535)$ & Females $(N=535)$ & Statistic $^{\mathrm{a}}$ \\
\hline Age, mean \pm SD & $43.41 \pm 8.07$ & $45.09 \pm 8.13$ & $41.73 \pm 7.68$ & $9.98 * * *$ \\
\hline Married, n (\%) yes & $345(32.49)$ & $175(32.96)$ & $170(32.02)$ & 0.95 \\
\hline Living with study partner, mean \pm SD & $806 \pm 75.97$ & $405 \pm 76.42$ & $401 \pm 75.52$ & 0.71 \\
\hline Years with study partner, mean \pm SD & $6.91 \pm 6.56$ & $7.09 \pm 6.68$ & $6.74 \pm 6.44$ & $2.71 * *$ \\
\hline \multicolumn{5}{|l|}{ Education, n (\%) } \\
\hline$<\mathrm{HS}$ & $326(30.67)$ & $141(26.55)$ & $185(34.77)$ & \\
\hline HS/GED & $437(41.11)$ & $249(46.89)$ & $188(35.34)$ & \\
\hline Some college & $300(28.22)$ & $141(26.55)$ & $159(29.89)$ & $4.04 *$ \\
\hline Employed, n (\%) yes & $302(28.46)$ & $181(34.09)$ & $121(22.83)$ & $19.89 * * *$ \\
\hline \multicolumn{5}{|l|}{ Income, n (\%) } \\
\hline$<\$ 400$ per month & $307(28.96)$ & $158(29.81)$ & $149(28.11)$ & \\
\hline$\$ 400-850$ per month & $446(42.08)$ & $212(40.00)$ & $234(44.15)$ & \\
\hline$\$ 851-1650$ per month & $205(19.34)$ & $103(19.43)$ & $102(19.25)$ & 0.40 \\
\hline$>\$ 1650$ per month & $102(9.62)$ & $57(10.75)$ & $45(8.49)$ & \\
\hline Insured, n (\%) yes & $800(75.40)$ & $365(68.87)$ & $435(81.92)$ & $25.98 * * *$ \\
\hline Previously incarcerated, n (\%) yes & $661(62.54)$ & $405(76.42)$ & $256(48.58)$ & $90.24 * * *$ \\
\hline Spent time in inpatient drug treatment program, $\mathrm{n}(\%)$ yes & $554(52.17)$ & $288(54.24)$ & $266(50.09)$ & 2.06 \\
\hline Spent time in other residential programs, $\mathrm{n}(\%)$ yes & $267(25.16)$ & $129(24.29)$ & $138(26.04)$ & 0.69 \\
\hline Hepatitis C, n (\%) positive & $231(21.73)$ & $134(25.24)$ & $97(18.23)$ & $7.48 * *$ \\
\hline \multicolumn{5}{|c|}{ HIV clinical characteristics (HIV-positive partners only; $n=535)$} \\
\hline \multicolumn{5}{|l|}{ CD4 count, $\mathrm{n}(\%)$} \\
\hline$<200$ & $47(9.07)$ & $24(11.71)$ & $23(7.35)$ & $8.15^{*}$ \\
\hline $200-500$ & $147(28.38)$ & $49(23.90)$ & $98(31.31)$ & \\
\hline $501-3000$ & $161(31.08)$ & $58(28.29)$ & $103(32.91)$ & \\
\hline Unknown (9999) & $163(31.47)$ & $74(36.10)$ & $89(28.43)$ & \\
\hline \multicolumn{5}{|l|}{ Viral load, n (\%) } \\
\hline $0-50$ & $131(25.49)$ & $53(25.98)$ & $78(25.16)$ & 1.60 \\
\hline $51-400$ & $38(7.39)$ & $13(6.37)$ & $25(8.06)$ & \\
\hline$>400$ & $111(21.60)$ & $40(19.61)$ & $71(22.90)$ & \\
\hline Unknown (9999) & $234(45.53)$ & $98(48.04)$ & $136(43.87)$ & \\
\hline
\end{tabular}

${ }^{a}$ Statistic $=\mathrm{Z}$ from GEE model, adjusted for within couple correlation, for continuous variables (age and years with study partner); Statis$t i c=$ Mantel Hansel $\chi^{2}$ for categorical variables (married $(\mathrm{df}=1)$, living with study partner $(\mathrm{df}=1)$, education, insured, previously incarcerated, spent time in residential drug treatment program, spent time in other residential treatment program, Hepatitis $\mathrm{C}(\mathrm{df}=2)$, employed $(\mathrm{df}=1)$, and income $(\mathrm{df}=3))$. Statistic $=$ unadjusted $\chi^{2}(\mathrm{df}=3)$ for the HIV Clinical Characteristics $(\mathrm{CD} 4$ count and viral load $)$

$* P<0.05$; ** $P<0.01$; *** $P<0.0001$

sexual practices to occur among couples. For example, to assess vaginal sex, female participants were asked: "In the past 90 days, about how many times did your study partner put his penis into your vagina?", and "In the past 90 days, when your study partner put his penis into your vagina, about how many of these times was a male condom used?" Similar items were used to assess anal and oral sexual episodes with study partners in the past 90 days. The primary HIV sexual risk behavior assessed was the proportion of the participants' sexual intercourse episodes with their study partner in the past 90 days that were protected using male or female condoms. This variable was calculated by dividing the total number of sexual intercourse episodes with the study partner in the past 90 days into the total number of times a male or female condom was used on those occasions.

A second important HIV sexual risk behavior assessed was the number of unprotected sexual intercourse episodes with the study partner in the past 90 days. This variable was calculated by subtracting the total number of sexual intercourse episodes with the study partner with whom a male or female condom was used in the past 90 days from the total number of episodes of sexual intercourse with the study partner in the past 90 days. The number of protected sexual episodes with study partners in the past 90 days was the complement of this variable. 
Table 2 Prevalence of gender-specific child and adult sexual abuse, by HIV serostatus, $\mathrm{N}=535$ couples

\begin{tabular}{|c|c|c|c|c|}
\hline \multicolumn{5}{|l|}{ Women only } \\
\hline & HIV positive $(\mathrm{n}=323)$ & HIV negative $(\mathrm{n}=212)$ & $\chi^{2}$ statistic & OR $[95 \% \mathrm{CI}]$ \\
\hline CSA: yes (\%) & $214(67.94)$ & $126(60.00)$ & $3.48^{+}$ & $1.41[0.98-2.03]$ \\
\hline ASA: yes (\%) & $173(54.23)$ & $85(40.48)$ & $9.59 * *$ & $1.74[1.22-2.48]$ \\
\hline \multicolumn{5}{|l|}{ CSA and ASA } \\
\hline Neither & $71(22.54)$ & $67(32.21)$ & $9.50 * *$ & Reference \\
\hline Either & $102(32.38)$ & $73(35.10)$ & & $1.31[0.84-2.07]$ \\
\hline Both & $142(45.08)$ & $68(32.69)$ & & $1.97[1.27-3.06]$ \\
\hline \multicolumn{5}{|l|}{ Men only } \\
\hline & HIV positive $(\mathrm{n}=212)$ & HIV negative $(\mathrm{n}=323)$ & $\chi^{2}$ statistic & OR $[95 \% \mathrm{CI}]$ \\
\hline CSA: yes (\%) & $73(34.93 \%)$ & $69(22.04)$ & $10.50 * *$ & $1.90[1.28-2.80]$ \\
\hline ASA: yes $(\%)$ & $11(5.19)$ & $5(1.55)$ & $5.81 *$ & $3.47[1.19-10.13]$ \\
\hline \multicolumn{5}{|l|}{ CSA and ASA } \\
\hline Neither & $134(64.11)$ & $242(77.56)$ & $13.09 * *$ & Reference \\
\hline Either & $66(31.58)$ & $66(21.15)$ & & $1.81[1.23-2.74]$ \\
\hline Both & $9(4.31)$ & $4(1.28)$ & & $4.06[1.23-13.44]$ \\
\hline
\end{tabular}

$+P<0.10 ; * P<0.05 ; * * P<0.01$

Table 3 Prevalence of couple-level child and adult sexual abuse, $\mathrm{N}=535$ couples

\begin{tabular}{|c|c|c|c|c|c|}
\hline & \multirow{2}{*}{$\begin{array}{l}\text { All couples }(\mathrm{n}=535) \\
\mathrm{N}(\%)\end{array}$} & \multicolumn{2}{|l|}{ HIV positive partner } & \multirow[t]{2}{*}{$\chi^{2}$ statistic } & \multirow[t]{2}{*}{ OR $[95 \% \mathrm{CI}]$} \\
\hline & & $\begin{array}{l}\text { Female }(\mathrm{n}=323) \\
\mathrm{N}(\%)\end{array}$ & $\begin{array}{l}\text { Male }(\mathrm{n}=212) \\
\mathrm{N}(\%)\end{array}$ & & \\
\hline \multicolumn{6}{|c|}{ Childhood Sexual Abuse (CSA) } \\
\hline Neither partner & $142(27.73)$ & $77(25.25)$ & $65(31.40)$ & $17.24 * * *$ & Reference \\
\hline One partner & $269(52.54)$ & $182(59.67)$ & $87(42.03)$ & & $1.77[1.16-2.68]$ \\
\hline Both partners & $101(19.73)$ & $46(15.08)$ & $55(26.57)$ & & $0.71[0.42-1.18]$ \\
\hline CSA (males only) & $142(27.20)$ & $69(22.04)$ & $73(34.93)$ & $10.50 * *$ & $1.90[1.28-2.80]$ \\
\hline CSA (females only) & $340(64.76)$ & $214(67.94)$ & $126(60.00)$ & $3.48^{+}$ & $1.41[0.98-2.03]$ \\
\hline \multicolumn{6}{|c|}{ Adult Sexual Abuse (ASA) } \\
\hline Neither partner & $261(49.43)$ & $142(44.65)$ & $119(56.67)$ & $10.02 * *$ & Reference \\
\hline One partner & $261(49.43)$ & $174(54.72)$ & $87(41.43)$ & & 1.68 [1.18-2.39] \\
\hline Both partners & $6(1.14)$ & $2(0.63)$ & $4(1.90)$ & & $0.42[0.07-2.33]$ \\
\hline ASA (males only) & $16(3.00)$ & $5(1.55)$ & $11(5.19)$ & $5.81 *$ & $3.47[1.19-10.13]$ \\
\hline ASA (females only) & $258(48.77)$ & $173(54.23)$ & $85(40.48)$ & $9.59 * *$ & $1.74[1.22-2.48]$ \\
\hline
\end{tabular}

$+P<0.10 ; * P<0.05 ; * * P<0.01 ; * * * P<0.001$

\section{Statistical Analysis}

The methods of statistical analysis are presented separately for each respective summary table. Table 1 presents a demographic summary of study participants, overall and stratified by gender, controlling for the within-couple correlation. Analysis of responses for continuous variables (age and years with study partner) was performed by fitting generalized estimating equations (GEE) as a function of gender, specifying couple as the clustering variable. Mantel-Haenszel $\chi^{2}$ statistics were reported for categorical variables (marital status, living with study partner, education, and income), controlling for the correlations within each couple and listing degrees of freedom, and p-values. Table 2 presents gender-specific rates of CSA and ASA comparing HIV-positive participants to HIV-negative participants. Within gender, responses from HIV-positive and HIV-negative participants were analyzed using $\chi^{2}$ test 
Table 4 Correlates of child and adult sexual abuse, $\mathrm{N}=1070$ participants

\begin{tabular}{|c|c|c|c|}
\hline Exposures & $\begin{array}{l}\text { CSA } \\
\text { Estimate }(95 \% \mathrm{CI})\end{array}$ & $\begin{array}{l}\text { ASA } \\
\text { Estimate }(95 \% \mathrm{CI})\end{array}$ & $\begin{array}{l}\text { Both CSA and ASA } \\
\text { Estimate }(95 \% \mathrm{CI})\end{array}$ \\
\hline \multicolumn{4}{|l|}{ Demographics } \\
\hline${ }^{\mathrm{a}}$ Female & $4.92(3.78,6.40)^{* * * *}$ & $30.82(18.22,52.15)^{* * * *}$ & $26.22(14.71,46.71)^{* * * *}$ \\
\hline${ }^{\mathrm{a}} \mathrm{HIV}$ positive & $2.04(1.59,2.61)^{* * * *}$ & $2.60(1.95,3.48)^{* * * *}$ & $2.52(1.84,3.44) * * * *$ \\
\hline${ }^{\mathrm{a}}$ Excellent or very good general health & $0.80(0.68,1.03)^{+}$ & $0.76(0.57,1.01)^{+}$ & $0.70(0.51,0.95)^{*}$ \\
\hline${ }^{\mathrm{a}}$ Hepatitis $\mathrm{C}$ positive & $0.99(0.74,1.33)$ & $1.20(0.87,1.67)$ & $1.24(0.88,1.76)$ \\
\hline${ }^{\mathrm{a}}$ Insured & $1.63(1.22,2.18)^{* * *}$ & $1.99(1.39,2.85)^{* * *}$ & $1.89(1.29,2.78)^{* *}$ \\
\hline${ }^{\mathrm{b}}$ Quality of Life & $-0.14(-0.53,0.24)$ & $0.04(-0.39,0.48)$ & $-0.01(-0.48,0.46)$ \\
\hline${ }^{\mathrm{b}}$ Dependent children & $0.10(-0.09,0.29)$ & $-0.06(-0.27,0.15)$ & $-0.03(-0.25,0.20)$ \\
\hline \multicolumn{4}{|l|}{ Relationship characteristics } \\
\hline${ }^{\mathrm{a}}$ Married & $1.35(1.05,1.73)^{*}$ & $1.11(0.84,1.47)$ & $1.25(0.93,1.69)$ \\
\hline${ }^{\mathrm{a}}$ Separated & $1.26(0.79,2.02)$ & $1.06(0.62,1.80)$ & $1.01(0.57,1.80)$ \\
\hline${ }^{\mathrm{a}}$ Married to study partner & $1.27(0.98,1.65)^{+}$ & $1.09(0.81,1.45)$ & $1.28(0.94,1.75)$ \\
\hline${ }^{\mathrm{b}}$ Relationship assessment & $-0.14(-0.71,0.43)$ & $0.24(-0.41,0.89)$ & $-0.00(-0.70,0.69)$ \\
\hline${ }^{b}$ Years with study partner & $0.33(-0.47,1.14)$ & $0.55(-0.35,1.46)$ & $0.43(-0.54,1.41)$ \\
\hline \multicolumn{4}{|c|}{ Past experiences that increase vulnerability-and drug related, housing and psychological problems } \\
\hline${ }^{a}$ Previously in drug treatment program & $1.67(1.31,2.14)^{* * * * *}$ & $2.05(1.54,2.73) * * * *$ & $2.27(1.66,3.10)^{* * * * *}$ \\
\hline${ }^{a}$ Previously in residential treatment program & $1.69(1.27,2.23)^{* * *}$ & $2.04(1.51,2.76)^{* * * * *}$ & $2.06(1.50,2.84) * * * *$ \\
\hline${ }^{\mathrm{a}}$ TCUDS $\geq 3$ & $1.54(1.11,2.14)^{* *}$ & $1.36(0.96,1.94)^{+}$ & $1.67(1.16,2.42)^{* *}$ \\
\hline${ }^{\mathrm{a}} \mathrm{CAGE} \geq 2$ & $1.13(0.81,1.57)$ & $0.84(0.57,1.24)$ & $0.93(0.62,1.40)$ \\
\hline${ }^{\text {a} P r e v i o u s l y ~ i n c a r c e r a t e d ~}$ & $0.99(0.77,1.28)$ & $1.09(0.82,1.45)$ & $1.06(0.78,1.44)$ \\
\hline \multicolumn{4}{|l|}{ Risk behaviors } \\
\hline${ }^{\mathrm{a}} \mathrm{STD}$ positive & $1.48(1.04,2.10)^{*}$ & $1.96(1.36,2.83)^{* * *}$ & $2.03(1.38,2.98)^{* * *}$ \\
\hline${ }^{\mathrm{a}}$ Traded sex for drugs, money, food & $2.51(1.31,4.81)^{* *}$ & $3.68(2.00,6.78) * * * *$ & $3.38(1.82,6.28)^{* * *}$ \\
\hline${ }^{\mathrm{a}}$ Concurrent opposite sex partners & $1.78(1.19,2.67)^{* *}$ & $1.30(0.84,2.01)$ & $1.56(1.00,2.45)^{*}$ \\
\hline \multicolumn{4}{|l|}{ Relationship based risks } \\
\hline${ }^{b}$ Protected sex (90d) & $-7.06(-11.32,-2.80)^{* *}$ & $-2.60(-7.41,2.21)$ & $-4.28(-9.48,0.93)$ \\
\hline${ }^{\mathrm{b}}$ Unprotected sex (90d) & $-2.59(-6.49,1.30)$ & $-0.23(-4.59,4.13)$ & $-1.26(-5.98,3.45)$ \\
\hline${ }^{b}$ Proportion protected sex (90d) & $0.02(-0.03,0.08)$ & $0.07(0.01,0.13)^{*}$ & $0.05(-0.01,0.12)$ \\
\hline${ }^{\mathrm{b}}$ Vaginal sex (90d) & $-4.99(-9.48,-0.49)^{*}$ & $1.00(-4.05,6.04)$ & $-0.32(-5.77,5.13)$ \\
\hline${ }^{\mathrm{b}}$ Anal sex (90d) & $0.06(-2.57,2.68)$ & $-0.69(-3.47,2.10)$ & $-0.89(-3.88,2.10)$ \\
\hline
\end{tabular}

${ }^{a}$ Estimate $=$ odds ratio of abuse comparing 'exposed to non-exposed' and corresponding p-value from $1 \mathrm{df} \chi^{2}$ test statistic

${ }^{\mathrm{b}}$ Estimate $=$ mean difference and corresponding p-value from two-sample $t$-test comparing mean 'exposure' for participants who reported abuse to those who did not report abuse

$\mathrm{CAGE}=$ alcohol abuse scale; $\mathrm{CAGE} \geq 2$ identifies alcohol problems

TCUDS $=$ drug abuse scale; TCUDS $\geq 3$ identifies drug problems

Relationship assessment scale-measures relationship satisfaction in intimate relationships; scores range from 7 (low satisfaction) to 35 (high satisfaction)

Quality of life $=$ sum of two responses related to feelings about life now and about life one year from now; scores may range from 2 (worst possible life now and one year from now) to 20 (best possible life now and one year from now)

$+P<0.10 ; * P<0.05 ; * * P<0.01 ; * * * P<0.001 ; * * * * P<0.0001$

statistics. Corresponding odds ratios (OR) and 95\% confidence intervals (CIs) compare rates of abuse for HIVpositive and HIV-negative participants. In Table $3, \chi^{2}$ test statistics $(\mathrm{df}=2)$ and corresponding $P$-values are presented testing for any statistical association between the distribution of each three level couple outcome (neither, one, or both partners reporting abuse) and gender of the
HIV-positive partner. Corresponding odds ratios are also presented comparing the couples where the HIV-positive partner is female to couples where the HIV-positive partner is male. We fit multinomial regression models for the three level couple CSA response in order to examine whether the gender of the HIV positive partner was associated with couple CSA scores via a cumulative logit model. All 
results from the regression model are summarized in the text below. Table 4 presents the estimated associations of individual-level correlates of abuse for each abuse outcome of interest (CSA, ASA and both CSA and ASA). This analysis focuses on individual outcomes and correlates because an abuse history as an individual outcome may have occurred outside the context of the current relationship. We considered a number of correlates from the following broad categories: demographics, relationship characteristics, past experiences that increase vulnerability, risk behaviors, and relationship based risks. Odds ratios, 95\% confidence intervals and $P$-values from $1 \mathrm{df}$ Chisquare tests are presented for binary correlates while mean differences, corresponding 95\% confidence intervals and $P$-values from two-sample $t$-tests comparing the mean values of each potential correlate among participants who reported abuse to those who did not report abuse are presented for continuous correlates. These analyses are presented for the entire study sample, however we did examine whether or not observed associations differed for men and women by fitting a model with the main effects of each potential correlate and gender, as well as the "correlate X gender' interaction term. Any outcome, correlate combination with significant 'correlate $\mathrm{X}$ gender' terms were further highlighted to illustrate gender as a modifier of the effect of the correlate on the abuse outcome. All analyses were completed using SAS V9 (SAS Institute, Cary NC) and all hypotheses tests were two-sided and conducted at the alpha $=0.05$ level.

\section{Results}

The prevalence of CSA (age 17 and younger) and ASA (age 18 and older) was reported as $482(45.0 \%$ ) and 274 (25.6\%), respectively, of the 1070 participants in the study.

\section{Women}

The majority of the women $(63.6 \%)$ in the study reported histories of CSA $(67.94 \%$ of HIV positive and $60 \%$ of HIV-negative women, $\left(\chi^{2}(\mathrm{df}=1)=3.48 ; P=.0622\right)$. Nearly half, or $48.2 \%$, of women in the sample reported adult sexual abuse. HIV-positive women were significantly more likely to have a history of ASA (54.23\%) compared to HIV-negative women $(40.48 \%),\left(\chi^{2}(\mathrm{df}=1)=9.59\right.$; $P<0.01)$. HIV-positive women were also significantly more likely to have reported either one kind of abuse history (CSA or ASA) (32.32\%) or both histories (45.08\%) compared to HIV-negative women (either history = $35.10 \%$; both histories $=32.69 \%),\left(\chi^{2}(\mathrm{df}=2)=9.50\right.$; $P<.01$. The corresponding odds ratios comparing HIVpositive to HIV-negative women, for either CSA or ASA history, compared to no history of either was equal to 1.31 (95\% CI: [0.84, 2.07]), suggesting no significant difference between the two groups, $P=$ ns. However, the estimated odds ratio for HIV-positive women versus HIV-negative, for both CSA and ASA histories, compared to no history was equal to 1.97 (95\% CI: [1.27, 3.06]), suggesting that HIV-positive women were significantly more likely to have histories of both CSA and ASA compared to HIV-negative women.

Men

More than one quarter of the men $(26.54 \%)$ in the study reported early sexual abuse CSA, with significantly more HIV-positive men reporting CSA (34.93\%) compared to HIV-negative men $(22.04 \%), \quad\left(\chi^{2} \quad(\mathrm{df}=1)=10.50\right.$; $P<.01)$. The odds of having a CSA history were nearly twice as high for HIV-positive compared to HIV-negative men $(\mathrm{OR}=1.90 ; 95 \%$ CI: [1.28-2.80]). ASA was reported by $16(3 \%)$ of men in the sample. HIV-positive men were significantly more likely to have a history of ASA $(5.19 \%)$ compared to HIV-negative men $(1.55 \%),\left(\chi^{2}(\mathrm{df}=1)=\right.$ 5.81; $P=0.02$ ). HIV-positive men were also significantly more likely to have reported either one kind of sexual abuse history (CSA or ASA) (31.58\%) or both kinds $(4.31 \%)$ compared to HIV-negative men (one history $=21.15 \%$; both histories $=1.28 \%),\left(\chi^{2}(\mathrm{df}=2)=\right.$ $13.09 ; P<.01$ ). The odds ratio of CSA history for HIVpositive compared to HIV-negative men was equal to 1.81 (95\% CI: [1.23, 2.74]). HIV-positive men had nearly twice the odds of having reported a history of CSA compared to HIV-negative men.

\section{Couples}

Table 3 presents the rates of couple-level CSA and ASA. Specifically, data were classified into 3-levels for CSA and ASA: whether neither, one, or both partners reported histories of CSA and ASA. Overall, $72 \%$ of couples reported one or both partners had a history of child sexual abuse. The distribution of couple-level CSA is significantly different in couples where the HIV-positive partner is male, compared to couples in which the HIV-positive partner is female, $\left(\chi^{2}(\mathrm{df}=2)=17.24 ; P<0.01\right)$. A higher prevalence of CSA for at least one partner was reported for couples where the female was HIV-positive compared to couples where the male was HIV-positive (74.8 and 68.6\%, respectively). However, couples where the HIV-positive partner was male had a higher CSA prevalence reported by both partners (26.57\% in couples with HIV-positive males, compared to $15.08 \%$ in couples with HIV-positive females). Early sexual abuse was reported by $67.9 \%$ of female partners and $22.0 \%$ of male partners in couples with 
HIV-positive females. In contrast, CSA was reported by $60.0 \%$ of female partners and $34.9 \%$ of male partners in couples with HIV-positive males. Finally, HIV-positive males reported a significantly higher prevalence of CSA (34.9\%) compared to HIV-negative males $(22.0 \%),\left(\chi^{2}\right.$ $(\mathrm{df}=1)=10.50 ; P<0.01)$. However, this difference was only marginally different for females $(67.9 \%$ for HIVpositive s compared to $60.0 \%$ for HIV-negative females), $\left(\chi^{2}(\mathrm{df}=1)=3.48 ; P=0.06\right)$.

The distribution of the 3-level couple ASA measure is significantly different in couples where the HIV-positive partner is male, $\quad\left(\chi^{2} \quad(\mathrm{df}=2)=10.02 ; \quad P<0.01\right)$. Approximately $45 \%$ of couples in which the female partner was HIV-positive did not report ASA compared to $57 \%$ of couples where the male was the HIV-positive partner. When the HIV-positive partner was female, $54.57 \%$ of couples reported one partner experiencing ASA, compared to $41.43 \%$ of couples where the male was HIV-positive. There were only six couples where both partners had experienced ASA.

We fit a cumulative logistic multinomial regression model for each 3-level couple CSA score (CSA experienced by neither, one, or both partners) as a function of couple-type (HIV-positive partner is either male or female) in order to examine the association between couple-type and the total number of incidents per couple. The odds of fewer total CSA incidents per couple was not statistically different between couples in which the female was HIVpositive and those in which the male was HIV-positive (odds ratio $=1.14,95 \%$ CI $[0.81,1.59]$ ).

\section{Discussion}

This study reports the prevalence of child and adult sexual abuse in one of the largest samples of African-American couples in the United States. A total of 535 serodiscordant couples were recruited from four major cities with high HIV prevalence rates-Atlanta, New York, Philadelphia and Los Angeles. The sample included men and women with average age in their $40 \mathrm{~s}$, most of who lived together, had a high school education or less, and were living at or well below the poverty level for the US [3]. Women were less likely than their male partners to be employed. Most of these couples had a history of incarceration, spent time in drug treatment programs, and lived in residential facilities, such as half-way houses and homeless shelters. The rates of Hepatitis C, low CD 4 count and reports of high viral loads suggest that this is a health compromised sample of men and women, even though most have access to HIV and non-HIV medications through public insurance. A person living with HIV may have increased responsibility of taking care of the uninfected partner, which placed couples and families at increased economic and health related risks. Thus this population's vulnerability not only to HIV infection, but also to other social and structural factors is clear.

This study also examines the relationship between sexual abuse histories by gender and HIV serostatus. Given that one of the major sources of HIV transmission is through sexual contact [1], most studies report on sexual behaviors, but do not assess or separate consensual from non-consensual sexual experiences. This is a necessary distinction because past histories can influence current behaviors. If the full range of sexual experiences is not taken into account, the effectiveness of the prevention services that couples receive may be limited [36]. The findings indicated a strong relationship between HIV serostatus and abuse history. In this population, $72.3 \%$ of couples reported that one or both partners had a history of child sexual abuse. Consistent with previous studies [14]. African American women, especially those who were HIVpositive, were more likely to report CSA histories than HIV-negative women. Other studies reporting the prevalence of sexual abuse primarily among African American men, have focused on men who had sex with men $[18,35]$. It is important to recognize same gender sexual experiences among these couples as well, but in this sample they were few in number. These findings help to highlight the common occurrence of early sexual abuse experiences in couples, particularly among those where one partner is HIV positive and the other is HIV negative.

Over half of the couples in which the female was HIVpositive (55.4\%) and $43.3 \%$ of the couples in which the HIV-positive person was male, reported a history of attempted or completed incidents of adult rape. While fewer persons reported ASA incidents than CSA incidents, the rates of ASA are nevertheless notable. When early sexual abuse occurs, the likelihood of being re-victimized increases [69, 70]. In this sample, HIV-positive women $(45.1 \%)$ were more likely to report sexual re-victimization after age 18 compared to HIV negative women $(32.7 \%)$ or men $(5.6 \%)$. Both partners were most likely to report early sexual abuse in couples where the male was HIV-positive.

When sexual risk taking among couples was examined, there were different patterns noted for individuals who reported abuse over their life course versus those who reported abuse only in childhood or adulthood. Individuals who reported histories of CSA and ASA tended to report psychological vulnerability, including psychological distress, and histories of being in drug and residential treatment programs. In addition, they were also more likely to; (1) report having had sex in exchange for money, food or drugs; (2) have an STI; (3) be HIV positive; and (4) to be women. These findings suggest that economic problems that impacted daily living were associated with histories of 
abuse. HIV positive female partners with this pattern across time seem to be the most psychologically impacted and at risk for STI and HIV transmission among women.

Further, patterns of sexual abuse both before and since age 18 were related to outcomes associated with substance abuse, housing, or other psychological problems that increase women's vulnerability in relationships. We also confirmed that HIV positive women were less likely to use condoms with their partners and to have STI histories. While these women's risks may have been diminished, STI transmission can still occur among couples where the woman is HIV infected and may have an STI, as well.

Women with histories of CSA but not ASA reported a different constellation of sexual risks, including engaging in unprotected sex [50] and less frequent vaginal sex with their primary partner [36]. However, they reported more concurrent partners [21]. More research is needed to determine if these women were more sexually active with partners outside of their primary relationship than they were in their current relationships. They may also have engaged in risky sexual practices before the relationship with partners in this study. Individuals who reported histories of ASA, but not CSA, were more likely to use condoms when engaging in sexual encounters.

These findings suggest that while histories of sexual abuse among African American couples need to be addressed, HIV-positive African American women, in particular, may require additional skills to effectively negotiate with partners about high-risk behaviors and to protect themselves from future abuse [48]. Risky but longestablished coping strategies may influence their physical health and well being $[46,47]$ and could create or maintain a power imbalance between sexual partners [66]. Research examining how past experiences can heighten risks for abuse and trauma in current relationships awaits further study $[67,68]$.

It is important to recognize that serodiscordant couples who are seeking therapy or counseling may not be asked about their serostatus or histories of sexual abuse. Training health professionals to address these issues may help to minimize HIV transmission, sexual re-victimization and help couples develop healthy sexual relationships. Recently, histories of sexual abuse have been integrated into HIV interventions that have been developed for African-American women and men $[18,36]$. These interventions have addressed the gender and cultural context needed to reduce individual risks and to enhance HIVrelated sexual and violence self-protection. The findings also highlight the importance of recognizing gender and sexual orientation in future interventions. There may be critical socialization issues involving cultural beliefs and values that men and women learn, as well as misinformation about gender-related sexual stereotypes that need to be clarified [19].

This study had several unique qualities. It is one of the largest and most comprehensive studies of serodiscordant couples at multiple sites with at-risk African Americans [1]. Most CSA research is conducted with college or clinic samples who fail to report the ethnicity of their participants [75]. This study, though not representative, is based on community sample of African American serodiscordant couples. Research has not focused on the prevalence, circumstances, and long-term correlates of sexual abuse in African Americans who are in committed relationships and are affected by HIV. The study also uses a comprehensive measure of CSA and ASA. Most research examining sexual abuse uses single-item questions, in contrast to the present measure. This accounts for the consensual nature of the sexual activity, victim and perpetrator age discrepancy, as well as the specific sexual behaviors that occurred. This measure has been used for almost three decades in numerous studies, which provides a sense of consistency in the method and design of this study [12]. However, limitations of the current research should be addressed. Recruitment was based on convenience sampling and thus limits the representativeness of the findings. Although efforts were made to recruit highly diverse couples with regard to age and length of relationships, our sample tended to be older and more established, highlighting the need to expand research with younger couples in newer relationships. Finally, the focus of this study is on self-identified African Americans, and similar research with other ethnic groups or individuals is needed.

Future research should examine the relationships between histories of child and adult sexual abuse in couples and specific behaviors like concurrency of partners that may heighten risks to uninfected partners. This paper reports the high prevalence of such sexual abuse, as well as sexual risks and psychological vulnerability, especially among HIV-positive women. The study findings stress the need for interventions that can help to reduce the effects of trauma as a result of sexual abuse histories and HIV serostatus [36]. African American couples can benefit from learning trauma related coping skills to maintain relationships that can enhance the quality of their lives while reducing HIV-related risk.

Acknowledgments This study was supported by the National Institute of Mental Health through the Cooperative Agreement mechanism (5 U10 MH64395-07, 5 U10 MH064393-07, 5 U10 MH064404, 5 U10 MH64394-06, and U10 MH-078819). The authors wish to thank the following members of the National Institute of Mental Health for providing support and scientific oversight of this trial: Ellen L. Stover, Ph.D., Dianne M. Rausch, Ph.D., and Christopher Gordon, Ph.D. The authors would also like to thank Micha Dalton and Tanishia Wright for assisting with manuscript preparation. 
We appreciate the contributions of Honghu Liu, $\mathrm{PhD}$ (Co-Inves.), and Lauren H. Wong (Supervisor) at UCLA to this paper.

Open Access This article is distributed under the terms of the Creative Commons Attribution Noncommercial License which permits any noncommercial use, distribution, and reproduction in any medium, provided the original author(s) and source are credited.

\section{References}

1. CDC. HIV/AIDS survelliance report: cases of HIV infection and AIDS in the United States and dependent areas. 2007: AIDS cases by race/ethnicity. 2008 .

2. CDC. STD surveillance 2006. 2008.

3. U.S. Census Bureau. American community survey: data profile highlights. http://www.census.gov/acs/www/index.html. Updated 2006.

4. Greenberg JB. Childhood sexual abuse and sexually transmitted diseases in adults: a review of and implications for STD/HIV programmes. Int J STD AIDS. 2001;12(12):777-83.

5. Buchacz K, van der Straten A, Saul J, Shiboski SC, Gomez CA, Padian N. Sociodemographic, behavioral, and clinical correlates of inconsistent condom use in HIV-serodiscordant heterosexual couples. J Acquir Immune Defic Syndr. 2001;28(3):289-97.

6. Nelson BS, Wampler KS. Systemic effects of trauma in clinic couples: an exploratory study of secondary trauma resulting from childhood abuse. J Marital Fam Ther. 2000;26(2):171-84.

7. Mills EA. From the physical self to the social body: expressions and effects of HIV-related stigma in South Africa. J Commun Appl Soc Psychol. 2006;16(6):498-503. http://dx.doi.org/ 10.1002/casp.899.

8. van der Straten A, Vernon KA, Knight KR, Gomez CA, Padian NS. Managing HIV among serodiscordant heterosexual couples: serostatus, stigma and sex. AIDS Care. 1998;10(5):533-48.

9. Anderson SR, Miller RB. The effectiveness of therapy with couples reporting a history of childhood sexual abuse: an exploratory study. Contemp Fam Ther. 2006;28(3):353-66.

10. Colman RA, Widom CS. Childhood abuse and neglect and adult intimate relationships: a prospective study. Child Abuse Negl. 2004;28(11):1133-51.

11. Muehlenhard CL, Highby BJ, Lee RS, Bryan TS, Dodrill WA. The sexual revictimization of women and men sexually abused as children: a review of the literature. Annu Rev Sex Res. 1998;9:177-223.

12. Wyatt GE. The sexual abuse of Afro-American and whiteAmerican women in childhood. Child Abuse Negl. 1985;9(4): 507-19.

13. Loeb TB, Williams JK, Carmona JV, et al. Child sexual abuse: associations with the sexual functioning of adolescents and adults. Annu Rev Sex Res. 2002;13:307-45.

14. Wyatt GE, Myers HF, Williams JK, et al. Does a history of trauma contribute to HIV risk for women of color? Implications for prevention and policy. Am J Public Health. 2002;92(4):660-5.

15. Briere J, Elliott DM. Sexual abuse, family environment, and psychological symptoms: on the validity of statistical control. J Consult Clin Psychol. 1993;61(2):284-8 (discussion 289-90).

16. Wyatt GE, Guthrie D, Notgrass CM. Differential effects of women's child sexual abuse and subsequent sexual revictimization. J Consult Clin Psychol. 1992;60(2):167-73.

17. Arriola KR, Louden T, Doldren MA, Fortenberry RM. A metaanalysis of the relationship of child sexual abuse to HIV risk behavior among women. Child Abuse Negl. 2005;29(6):725-46.
18. Williams JK, Wyatt GE, Rivkin I, Ramamurthi HC, Li X, Liu H. Risk reduction for HIV-positive African American and Latino men with histories of childhood sexual abuse. Arch Sex Behav. 2008;37(5):763-72.

19. Sorsoli L, Kia-Keating M, Grossman FK. "I keep that hushhush": male survivors of sexual abuse and the challenges of disclosure. J Couns Psychol. 2008;55(3):333-45.

20. Holmes WC, Slap GB. Sexual abuse of boys: definition, prevalence, correlates, sequelae, and management. JAMA. 1998; 280(21):1855-62.

21. Davis JL, Petretic-Jackson PA. The impact of child sexual abuse on adult interpersonal functioning: a review and synthesis of the empirical literature. Aggress Viol Behav. 2000;5(3):291-328.

22. Briere JN. Child abuse trauma: theory and treatment of the lasting effects, vol. 2. London: SAGE Publications, Inc.; 1992.

23. DiLillo D, Long PJ. Perceptions of couple functioning among female survivors of child sexual abuse. J Child Sex Abus. 1999;7(4):59-76.

24. Bensley LS, Van Eenwyk J, Simmons KW. Self-reported childhood sexual and physical abuse and adult HIV-risk behaviors and heavy drinking. Am J Prev Med. 2000;18(2):151-8.

25. Filipas HH, Ullman SE. Child sexual abuse, coping responses, self-blame, posttraumatic stress disorder, and adult sexual revictimization. J Interpers Violence. 2006;21(5):652-72.

26. West CM, Williams LM, Siegel JA. Adult sexual revictimization among black women sexually abused in childhood: a prospective examination of serious consequences of abuse. Child Maltreat. 2000;5(1):49-57.

27. Urquiza AJ, Goodlin-Jones BL. Child sexual abuse and adult revictimization with women of color. Violence Vict. 1994; 9(3):223-32.

28. DiIorio C, Hartwell T, Hansen N, NIMH Multisite HIV Prevention Trial Group. Childhood sexual abuse and risk behaviors among men at high risk for HIV infection. Am J Public Health. 2002;92(2):214-9.

29. Nelson BS, Wampler KS. Further understanding the systemic effects of childhood sexual abuse: a comparison of two groups of clinical couples. J Child Sex Abus. 2002;11(3):85-106.

30. Crosby RA, DiClemente RJ, Wingood GM, et al. Condom use and correlates of African American adolescent females' infrequent communication with sex partners about preventing sexually transmitted diseases and pregnancy. Health Educ Behav. 2002;29(2):219-31.

31. Amaro H, Raj A. On the margin: power and women's HIV risk reduction strategies. Sex Roles. 2000;42(7):723-749. http://dx. doi.org/10.1023/A:1007059708789.

32. Wyatt GE. Sociocultural and epidemiological issues in the assessment of domestic violence. J Soc Distress Homeless. 1994;3(1):7-21. http://dx.doi.org/10.1007/BF02087356.

33. Quina K, Harlow LL, Morokoff PJ, Burkholder G, Deiter PJ. Sexual communication in relationships: when words speak louder than actions. Sex Roles. 2000;42(7-8):523-49.

34. van der Straten A, Gomez CA, Saul J, Quan J, Padian N. Sexual risk behaviors among heterosexual HIV serodiscordant couples in the era of post-exposure prevention and viral suppressive therapy. AIDS. 2000;14(4):F47-54.

35. Sikkema KJ, Wilson PA, Hansen NB, et al. Effects of a coping intervention on transmission risk behavior among people living with HIV/AIDS and a history of childhood sexual abuse. J Acquir Immune Defic Syndr. 2008;47(4):506-13.

36. Wyatt GE, Longshore D, Chin D, et al. The efficacy of an integrated risk reduction intervention for HIV-positive women with child sexual abuse histories. AIDS Behav. 2004;8(4):453-62.

37. Heise L, Moore K, Toubia N. Sexual coercion and reproductive health, a focus on Research. New York: Population Council; 1995. http://www.popcouncil.org/pdfs/scoer.pdf. 
38. Brown NL, Wilson SR, Kao YM, et al. Correlates of sexual abuse and subsequent risk taking. Hisp J Behav Sci. 2003;25(3):331-51.

39. Trute B, Docking B, Hiebert-Murphy D. Couples therapy for women survivors of child sexual abuse who are in addictions recovery: a comparative case study of treatment process and outcome. J Marital Fam Ther. 2001;27(1):99-110.

40. Allen S, Tice J, Van de Perre P, et al. Effect of serotesting with counselling on condom use and seroconversion among HIV discordant couples in Africa. BMJ. 1992;304(6842):1605-9.

41. Dunkle KL, Stephenson R, Karita E, et al. New heterosexually transmitted HIV infections in married or cohabiting couples in urban Zambia and Rwanda: an analysis of survey and clinical data. Lancet. 2008;371(9631):2183-91.

42. Gray RH, Wawer MJ, Brookmeyer R, et al. Probability of HIV-1 transmission per coital act in monogamous, heterosexual, HIV-1discordant couples in Rakai, Uganda. Lancet. 2001;357(9263): 1149-53.

43. Lurie MN, Williams BG, Zuma K, et al. Who infects whom? HIV-1 concordance and discordance among migrant and nonmigrant couples in South Africa. AIDS. 2003;17(15):2245-52.

44. Roth DL, Stewart KE, Clay OJ, van Der Straten A, Karita E, Allen S. Sexual practices of HIV discordant and concordant couples in Rwanda: effects of a testing and counselling programme for men. Int J STD AIDS. 2001;12(3):181-8.

45. Serwadda D, Gray RH, Wawer MJ, et al. The social dynamics of HIV transmission as reflected through discordant couples in rural Uganda. AIDS. 1995;9(7):745-50.

46. Molnar BE, Buka SL, Kessler RC. Child sexual abuse and subsequent psychopathology: results from the national comorbidity survey. Am J Public Health. 2001;91(5):753-60.

47. Myers HF, Sumner LA, Ullman JB, Loeb TB, Carmona JV, Wyatt GE. Trauma and psychosocial predictors of substance abuse in women impacted by HIV/AIDS. J Behav Health Serv Res. 2009;36(2):233-46.

48. Wyatt GE, Axelrod J, Chin D, Carmona JV, Loeb TB. Examining patterns of vulnerability to domestic violence among African American women. Violence Against Women. 2000;6(5): 495-514.

49. Buzi RS, Tortolero SR, Roberts RE, Ross MW, Addy RC, Markham CM. The impact of a history of sexual abuse on highrisk sexual behaviors among females attending alternative schools. Adolescence. 2003;38(152):595-605.

50. Brown LK, Lourie KJ, Zlotnick C, Cohn J. Impact of sexual abuse on the HIV-risk-related behavior of adolescents in intensive psychiatric treatment. Am J Psychiatry. 2000;157(9):1413-5.

51. Messman-Moore TL, Long PJ. The role of childhood sexual abuse sequelae in the sexual revictimization of women: an empirical review and theoretical reformulation. Clin Psychol Rev. 2003;23(4):537-71.

52. Donaldson PE, Whalen MH, Anastas JW. Teen pregnancy and sexual abuse: exploring the connection. Smith Coll Stud Soc Work. 1989;59(3):289-300.

53. Johnsen LW, Harlow LL. Childhood sexual abuse linked with adult substance use, victimization, and AIDS-risk. AIDS Educ Prev. 1996;8(1):44-57.

54. Black CA, DeBlassie RR. Sexual abuse in male children and adolescents: indicators, effects, and treatments. Adolescence. 1993;28(109):123-33.

55. Holmes WC. Men's childhood sexual abuse histories by oneparent versus two-parent status of childhood home. J Epidemiol Commun Health. 2007;61(4):319-25.

56. Dube SR, Anda RF, Whitfield CL, et al. Long-term consequences of childhood sexual abuse by gender of victim. Am J Prev Med. 2005;28(5):430-8.
57. Beitchman JH, Zucker KJ, Hood JE, daCosta GA, Akman D, Cassavia E. A review of the long-term effects of child sexual abuse. Child Abuse Negl. 1992;16(1):101-18.

58. Courtois FJ, Macdougall JC, Sachs BD. Erectile mechanism in paraplegia. Physiol Behav. 1993;53(4):721-6.

59. Bellamy SL, NIMH Multisite HIV/STD Prevention Trial for African American Couples Study Group. A dynamic block-randomization algorithm for group-randomized clinical trials when the composition of blocking factors is not known in advance. Contemp Clin Trials. 2005;26(4):469-479. 10.1016/j.cct.2005. 02.005 .

60. NIMH Multisite HIV/STD Prevention Trial for African American Couples Group. Eban HIV/STD risk reduction intervention: conceptual basis and procedures. J Acquir Immune Defic Syndr. 2008;49 Suppl 1:S15-S27.

61. NIMH Multisite HIV/STD Prevention Trial for African American Couples Group. Eban health promotion intervention: conceptual basis and procedures. J Acquir Immune Defic Syndr. 2008;49 Suppl 1:S28-S34.

62. NIMH Multisite HIV/STD Prevention Trial for African American Couples Group. Measure of HIV/STD risk-reduction: strategies for enhancing the utility of behavioral and biological outcome measures for African American couples. J Acquir Immune Defic Syndr. 2008;49 Suppl 1:S35-S41.

63. NIMH Multisite HIV/STD Prevention Trial for African American Couples Group. Risky sexual behavior and correlates of STD prevalence among African American HIV serodiscordant couples. AIDS Behav. 2009.

64. NIMH Multisite HIV/STD Prevention Trial for African American Couples Group. Special issue. J Acquir Immune Defic Syndr. 2008;49 Suppl 1:S1-S74.

65. NIMH Multisite HIV/STD Prevention Trial for African American Couples Group. Designing an audio computer-assisted selfinterview (ACASI) system in a multisite trial: a brief report. J Acquir Immune Defic Syndr. 2008;49 Suppl 1:S52-S58.

66. Graupner H, Bullough VL, eds. Adolescence, sexuality, and the criminal law: multidisciplinary perspectives. Binghamton, NY: Haworth Press; 2004. http://www.loc.gov/catdir/toc/ecip053/ 2004026212.html.

67. Burgess-Jackson K. Rape: a philosophical investigation. Aldershot, Hant, England; Brookfield, USA: Dartmouth; 1996. p 244.

68. Glaser D. Child abuse and neglect and the brain-a review. J Child Psychol Psychiatry. 2000;41(1):97-116.

69. Myers HF, Wyatt GE, Loeb TB, et al. Severity of child sexual abuse, post- traumatic stress and risky sexual behaviors among HIV-positive women. AIDS Behav. 2006;10(2):191-9.

70. Wyatt GE, Peters SD. Methodological considerations in research on the prevalence of child sexual abuse. Child Abuse Negl. 1986;10(2):241-51.

71. Hendrick SS. A generic measure of relationship satisfaction. J Marriage Fam. 1988;50(1):93-8.

72. Hendrick SS, Hendrick C, Adler NL. Romantic relationshipslove, satisfaction, and staying together. J Pers Soc Psychol. 1988;54(6):980-8.

73. Ewing JA. Detecting alcoholism. The CAGE questionnaire. JAMA. 1984;252(14):1905-7.

74. Peters RH, Greenbaum PE, Steinberg ML, et al. Effectiveness of screening instruments in detecting substance use disorders among prisoners. J Subst Abuse Treat. 2000;18(4):349-58.

75. DiLillo D. Interpersonal functioning among women reporting a history of childhood sexual abuse: empirical findings and methodological issues. Clin Psychol Rev. 2001;21(4):553-76. 